\title{
Design, optimisation and performance analysis of orifice pulse tube cryogenic refrigerators
}

\author{
B. Jayaraman ${ }^{1}$ and P. Senthil Kumar ${ }^{2}$ \\ ${ }^{1}$ Dept. of Mechanical Engineering, Sathyabama University, Chennai - 600 119, India; \\ ${ }^{2}$ Dept. of Mechanical Engineering, KSR College of Engg., Tiruchengode - 637209, TN., India \\ tabjayaraman@yahoo.co.in; cryosenthil@yahoo.com
}

\begin{abstract}
Pulse Tube Refrigerator (PTR), a regenerative cryocooler is used in cryogenic cooling applications. Thermodynamic and numerical models help in estimating the operation parameters, analysing and thereby predicting the performance of a PTR. A one dimensional simulation model for analytical studies, design and optimization of the regenerator geometry for improving the performance of the PTR is developed. The simulation program is based on the equations obtained from applying the ideal gas laws, energy and mass balances in the Orifice PTR (OPTR). Predictions by the simulation program of the thermodynamic performance are compared with published experimental results (Kral et al, 1992) to validate the program. At $274 \mathrm{~K}$, the refrigerating effect predicted by the program is $12.689 \mathrm{~W}$, whereas the experimental value is $11.57 \mathrm{~W}$, a difference of around $9 \%$. Conflicting requirements for regeneration are satisfied by selecting appropriate material and size of wire screen mesh type regenerator. Based on empirical understanding hybrid regenerators have been used instead of single mesh, showing improved performances. A mathematical model simulating the regenerator is developed and solved numerically. Unconstrained optimisation technique with univariate search method is adopted to design optimal hybrid regenerators and is integrated with the simulation program. Using a hybrid regenerator, instead of single mesh regenerator used in Kral's experiments, the regenerator effectiveness increases by $0.16 \%$ and pressure drop decreases by $29.2 \%$ when compared to single mesh regenerators. Hybrid regenerators improve the refrigeration capacity of the OPTR system by as much as $40 \%$. The validated simulation program can be used for the design and development of high performance OPTR.
\end{abstract}

Key words: Cryocooler; orifice pulse tube refrigerator; regenerator; simulation; refrigeration.

Nomenclature

A: Cross sectional area, $\mathrm{m}^{2}$; $\mathrm{C}$ : Coefficient; COP: Coefficient of Performance; L: Length; $\mathrm{m}$ : Massflow rate, $\mathrm{kg} \mathrm{s}^{-1}$; M: mass of gas in Moles; mho: mass of gas displaced; P: Pressure, Pa;

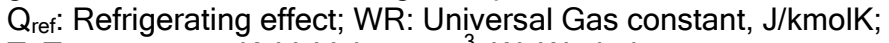
$\mathrm{T}$ : Temperature, $\mathrm{K} ; \mathrm{V}$ : Volume, $\mathrm{m}^{3}$; W: Work done.

Greek

$\varphi$ : crank angle rotation; $\gamma$ : ratio of specific heats; $\tau$ : time instant Subscripts

cl: clearance; che : cold end heat exchanger;

cpt: cold part of pulse tube; or: orifice

p: pressure; pt: gas already in pulse tube

pc: pre cooler; res: Reservoir; hhe: hot end heat exchanger;

hpt: hot pulse tube end; mpt: mid volume of gas in pulse tube; v: flow; cyl: cylinder

Introduction

Cryogenic temperatures are required in a variety of applications in Infrared sensors for military and space, medical applications, transportation etc. These requirements have been attained with Cryogenic Refrigerators or Cryocoolers. Cryocoolers supply refrigeration with a working gas that goes through a specific thermodynamic cycle. Gifford McMohan, stirling and pulse tube refrigerators are the commonly used regenerative cycle Cryocoolers. At present pulse tube refrigerators compete with stirling and Gifford-McMahon coolers, both in terms of temperature range and efficiency. Pulse tube refrigerators have no moving parts in the low temperature region resulting in lower mechanical vibration, lower mass per capacity and thereby longer life compared to other coolers. However, its efficiencies have to improve above $20 \%$ of Carnot efficiency to be the preferred choice for applications in the $80 \mathrm{~K}$ range. The performance of Pulse tube refrigerators has been greatly improved by innovative experimental design techniques like double-inlet design, inertance design, use of advanced regenerator materials, use of symmetry nozzle etc.

The theoretical developments lagged behind the experimental advances. To predict the performance of pulse-tube refrigerators different analytical and numerical models have been developed. Different simulation approaches which model the PTR with different levels of detail currently coexist. Thermodynamic models are timeaveraged using the laws of thermodynamics to analyse and predict the performance of a pulse tube. For a more accurate prediction of pulse tube performance analysis of compressible oscillating gas flow using full time dependent models of fluid dynamics has been carried out. The system of conservation laws forms the basis of fluid dynamical models. Due to the complexity of the conservation equations, analytical solutions are essentially impossible. This is why numerical models are otherwise called Computational Fluid Dynamics (CFD) which has gained importance of late. The existing CFD models and solution methods are based on the coupled differential equations representing mass, momentum and energy conservation. They use one dimensional model and rely on the validity of empirical correlations for
Research article

CIndian Society for Education and Environment (iSee)
"Cryogenic refrigerators " http://www.indjst.org
Jayaraman \& Senthil Kumar Indian J.Sci.Technol. 
computing flow friction and heat transfer. Multidimensional CFD models have also been used for accurate prediction of system behaviour. Even though these models are computationally intensive, the one dimensional model can still find periodic steady state solutions fast enough, that they are practical for numerical optimisation of machine designs. Thus a numerical model provides a powerful tool for estimating the parameters of cooling systems such as temperature, velocity, mass flow and enthalpy flow which leads to a deeper understanding of heat transfer and fluid-wall interaction in oscillating flow. Selecting appropriate mesh material and size has satisfied the conflicting requirements of a wire screen mesh regenerator used in PTR. Based on empirical understanding the hydraulic radius of mesh has been varied along the stack length, also called the hybrid regenerator and improved experimental performances have been reported. Analytical studies and design of optimal regenerator geometry for hybrid regenerators is lacking in the open published literature or in an accessible form. Proprietary considerations may be another reason for the same. The objective of the present work is a focus on development of a one dimensional simulation model of cyclic thermodynamic processes occurring in a PTR that will be useful for parametric analysis and design optimisation. A mathematical model of the OPTR is developed using the gas laws and thermodynamic equation. A control volume based approach for modelling oscillating compressible flow in one space dimension in the wire mesh type regenerator is presented. CFD analysis of the regenerator with a minimum of simplifying assumptions is conducted. The developed model is implemented and coded in a computer program for calculating the dynamic characteristics of the cooling system to predict its performance for given geometric parameters and operating conditions. The results are compared with published experimental data for validation. A design methodology for the optimization of hybrid regenerator is proposed. Selecting a combination of mesh sizes for hybrid regenerator to be used in OPTR, the lengths of individual mesh size are calculated confirming to physical constraints and the performance predicted. Analysis is carried out to study the effect of different mesh combinations on regenerator performance and the combination having optimal performance of the OPTR is identified. To model a pulse tube refrigerator, it is necessary to describe the physical model in which the gas flows and its behaviour with the components is derived in equation form.

Analysis of the OPTR

Attempts at analysis and simulation of the pulse tube refrigeration process have been made to design the OPTR for a given application by many researchers. Analyses of coolers have varied in their degree of complexity from simple calculations to nodal network analyses and detailed thermodynamic calculations. The models mainly used for the analysis and prediction of performance of pulse tube refrigerators are the phasor type, linear network type, one dimensional gas-dynamics type, CFD packages, thermodynamic equations, thermoacoustic model, empirical relations from experimental analyses etc. Some studies have also focused on the performance of regenerators under oscillating flow conditions. Gifford (Gifford \& Longsworth, 1964) proposed that 'heat surface pumping' is responsible for the cold production, when others focused their study on the angle shift between pressure and gas velocity. Storch and Radebaugh (Radebaugh, 1990) used the method of enthalpy flow and phasor analysis to represent some performances of pulse tubes. However, the quantitative accuracy of the analytical results was not satisfactory. The numerical modelling presented by $\mathrm{Wu}$ and Zhu (Radebaugh, 1990) neglected the pressure drop in the refrigerator. Wu et al. (Radebaugh, 1990) proposed a finite volume method to model the whole apparatus (compressor, regenerator, pulse tube, heat exchangers and orifices). Ju et al. used the full implicit time dependent and upwind second order finite difference scheme to discrete the conservation equations of mass, momentum and energy for oscillating flow in an orifice and double inlet pulse tube refrigerator.

Zhu (Zhu and Chen, 1994) introduced an isothermal model for the OPTR. In this analysis, convergence value used in the calculation varies for each angle of crank rotation. The instantaneous pressure is the sum of masses up to volume 'cpt' of the pulse tube section. Volumes 'hpt' and 'mpt' of the pulse tube section and HHE if considered, would lead to higher pressures in the system. Thus the realistic prediction of OPTR performance is not achieved by this method. The isothermal model was analysed using cyclic analysis to include losses, thereby predicting the net performance of the OPTR. None of these models have been completely validated yet and optimal design still requires experimental know how. Hence, there is a need for a validated mathematical model, which can be used to simulate, design and optimize a pulse tube refrigerator for a given application. Two models describing the behaviour of fluid in the OPTR have been developed: Analytical and Numerical. The analytical model is an adiabatic model, extending the Isothermal model (Zhu \& Chen, 1994) which includes Volumes 'hpt' and 'mpt' of the pulse tube section and HHE, leading to higher pressures in the system. Losses in the system are included and a numerical model of the regenerator is integrated to the OPTR simulation program to predict its actual performance. The numerical model concerns a one dimensional finite-difference solution scheme of the coupled differential equations representing mass, momentum and energy conservation with empirical correlations for computing flow friction and heat transfer.
Research article

CIndian Society for Education and Environment (iSee)
"Cryogenic refrigerators" http://www.indjst.org
Jayaraman \& Senthil Kumar Indian J.Sci.Technol. 


\section{Adiabatic model}

Developments in PTR's have gone through important stages of basic, orifice, inertance, double inlet and multistage forms. The Basic PTR was discovered by Gifford and Longsworth in the early 1960s. In 1984, Mikulin (Radebaugh, 1990) introduced the Orifice type in which an orifice and a reservoir were added to the closed end of the basic pulse. The inertance tube (a long and narrow tube replacing the orifice valve of OPTR, double inlet pulse tube refrigerator and multi-stage units achieved higher performance than the Basic PTR due to more favourable phase relationship between the oscillatory pressure and the mass flow rate. Interest in the OPTR, compared to the other types of PTR has grown rapidly since then due to its simplicity in construction, ease of manufacture and control and large refrigeration capacity. In the OPTR and other designs, the pressure heat pumping resulting from the proper phase angle between the pressure, temperature and mass flow rate is the major mechanism for energy transfer compared to the surface heat pumping (Radebaugh, 1990). The working process of an OPTR is very complex due to the oscillating gas and the addition of the orifice. The compression and expansion process of gas inside the pulse tube is similar to that in a Brayton cycle.

The compressor generates a pressure $p$ in the system which varies sinusoidally with time. When the pressure in the pulse tube is greater than the pressure in reservoir, fluid from the compressor enters the pulse tube section through a precooler heat exchanger ' $X_{1}$ ' at temperature $T_{H}$ and a regenerator 'reg'. The mass of gas coming into the pulse tube section from the cold heat exchanger (CHE) ' $X_{L}$ ' is at constant temperature $T_{L}$. Assuming inviscid plug flow of gas inside the pulse tube, the gas may be divided into 3 sections, 'cpt', 'mpt' and 'hpt'. Volume 'hpt' flows into and out of the hot heat exchanger (HHE), $X_{3}$. Volume 'cpt' flows into and out of the pulse tube through the regenerator, 'reg' and volume 'mpt' never leaves the pulse tube, moving up and down the tube as the pressure fluctuates. Gas 'cpt' entering the tube through the reg, compresses the already present gas 'mpt' and 'hpt' in the tube thus doing work on it. Each volume is supposed to take account of several complex processes actually acting in the tube: heat exchange in the associated heat exchanger, surface heat pumping in the tube and mixing phenomena for the gas. The cooling at $X_{L}$ takes place due to the fact that the gas leaves the CHE to the right with a temperature $T_{L}$ and comes back with a temperature lower than $T_{L}$. The cooling capacity of a pulse tube is limited by the amount of heat that can be pumped to $X_{3}$. The phase angle between the cyclic variation in pressure and velocity is the controlling factor of heat pumping. For sinusoidal pressure variations the heat pumping effect should be a maximum when pressure and velocity are in phase and a minimum when the phase angle between them is $90^{\circ}$. In the OPTR the correct phase relationship is achieved by adjusting the orifice ' $\mathrm{O}_{1}$ ' impedance and reservoir 'res' volume.

In the present model, the volume of gas in the pulse tube and HHE is included in the calculation of instantaneous pressure for each step of crank rotation. The volume variations in the cylinder are assumed to be sinusoidal. The temperature profile of the gas in the components of OPTR is obtained from the ideal gas laws. The work done and cooling capacity is calculated based on the P-V diagram area of the cylinder and the 'cpt' volume of the pulse tube. The losses are evaluated to obtain the actual cooling capacity and network done.

The assumptions to simplify the mathematical model of the OPTR and justifications for them are as follows:-

1. The model is one dimensional which finds periodic steady state solutions fast and is practical for numerical optimisation of OPTR design.

2. Working fluid is an ideal gas undergoing inviscid plug flow as it is compressed or expanded in the pulse Tube.

3. Frequency of operation of the OPTR is high enough to assume non-mixing of the incoming fluid with the fluid already present in the pulse tube.

4. Compression and expansion processes in the pulse tube are adiabatic.

When the gas is compressed, if the process is to be isothermal, it should reject all the heat equal to the work done during compression. As the frequencies of oscillating fluid are high, the heat transfer is not complete. As the gas will do work as it expands, Isothermal expansion implies energy supply from an external source. The pulse tube being insulted during its operation, the compression and expansion are not isothermal as assumed by Zhu (Zhu and Chen, 1994).

5 . The volume variation in the cylinder is sinusoidal. The piston movement inside the cylinder being harmonic, the sinusoidal motion equation describes volume variation more realistically.

4. The internal volumes of precooler, regenerator, $\mathrm{CHE}$ and HHE are assumed to be negligible. Fluid hold up in the void spaces affects performance but due to oscillatory flow, the effect on heat transfer can be neglected.

5 . The initial individual volumes of gas in the pulse tube, 'cpt', 'mpt' and 'hpt' are assumed based on empirical data. As the temperature of gas inside the pulse tube varies from the ambient temperature in the hot end to cryogenic temperatures in the cold end of the tube, the volumes are divided into 3 and temperatures assumed for these volumes.

6. During a cycle of operation, the pressure is assumed to be uniform throughout the system at a given instant. This assumption hold good if the pressure drop is minimum and frequency of operation is low.

7. Reduction in volume due to cooling of fluid in the HHE is not taken into account. This assumption reduces the complexity of modelling

8. The precooler, $\mathrm{CHE}$ and $\mathrm{HHE}$ are ideal. Due to small volumes compared to gas in the other components, the
Research article

CIndian Society for Education and Environment (iSee)
"Cryogenic refrigerators" http://www.indjst.org
Jayaraman \& Senthil Kumar Indian J.Sci.Technol. 
temperatures of gas inside the heat exchangers are assumed to be isothermal.

\section{Cyclic analysis}

The piston is initially assumed to be at its extreme position before start of compression. The piston movement is divided into step movements corresponding to particular crank rotation angle, during its rotation of $360^{\circ}$ for a cycle period. The pressure in the system during each step of the cycle is calculated based on the assumed volume variations of the fluid in the cylinder. The compressor volume at any crank angle for the given interval is given by :

$$
P(q)=\frac{M R}{\frac{V_{c y l}(q)}{T_{c y l}(q)}+\frac{V_{p c}}{T_{p c}}+\frac{V_{r}}{T_{r}}+\frac{V_{c h e}}{T_{c h e}}+\frac{V_{c p t}(q)}{T_{c p t}(q)}+\frac{V_{m p t}(q)}{T_{m p t}(q)}+\frac{V_{h p t}(q)}{T_{h p t}(q)}+\frac{V_{\text {hhe }}(q)}{T_{\text {hhe }}}--7}
$$

$$
\mathrm{V}_{\text {cyl }}=\mathrm{V}_{\mathrm{cl}}+0.5 \mathrm{~V}_{\text {cyl }}(1-\cos \varphi)----1
$$

The gas element undergoes isentropic compression and expansion in the compressor and pulse tube, isothermal compression in the precooler, hot end heat exchanger and regenerator. With an assumed increase in pressure $\Delta \mathrm{P}$ in the OPTR, the temperature and volume of gas undergoing adiabatic process in the $i^{\text {th }}$ component at instant ' $q$ ' is evaluated from the ideal gas laws. Due to assumption ' 6 ' the precooler, CHE and HHE is at their respective isothermal temperature. The regenerator temperature is the log mean temperature of cold end heat exchanger and precooler temperature.

The mass flow through the orifice when pressure in the pulse tube ' $P$ ' is greater than reservoir pressure $P_{\text {res }}$

$$
m_{\text {or }}=C_{v} A_{\text {or }} \sqrt{2 \frac{\gamma}{\gamma-1} \frac{P}{v}\left[\left(\frac{P_{\text {res }}}{P}\right)^{\frac{2}{\gamma}}-\left(\frac{P_{\text {res }}}{P}\right)^{\frac{\gamma+1}{\gamma}}\right]}
$$

enclosed gas. At steady state operation of the system, the pressure is expressed using the ideal gas law as:

where $\mathrm{V}$ and $\mathrm{T}$ is the volume and temperature of the gas in the respective components of the OPTR at instant ' $\mathrm{q}$ '. The product of the total mass of gas in Moles ' $M$ ' and the Universal Gas Constant ' $R$ ' is assumed to be a constant, as the exact value of $M$ is not known. As $P(q)$ occurs in both the LHS and RHS of eqn. 7, it is calculated by the Newton-Raphson method. The pressures are then calculated for the complete cycle based on the interval chosen. The pressure and temperature at the last interval should be equal to the pressure and temperature at the start of the cycle within a tolerance limit. If not, the calculation of pressure restarts with a new value of initial pressure and temperature. The mean pressure would be equal to $P_{\text {mean }}=P_{\text {total }} I$ (total points -1)

and when $P$ is less than $P_{\text {res }}$

$$
m_{\text {or }}=-C_{v} A_{\text {or }} \sqrt{2 \frac{\gamma}{\gamma-1} \frac{P_{\text {res }}}{v_{\text {res }}}\left[\left(\frac{P}{P_{\text {res }}}\right)^{\frac{2}{\gamma}}-\left(\frac{P}{P_{\text {res }}}\right)^{\frac{\gamma+1}{\gamma}}\right]}
$$

where $P_{\text {total }}=\Sigma P(q)$. The actual value of $M R$ is calculated from the value of $P_{\text {mean }}$ and the average pressure of the gas $\mathrm{P}_{\text {avg. }}$. The ratio of $P_{\text {avg }}$ to $P_{\text {mean }}$ is the correct fraction of

The mass flow rate at $\mathrm{HHE}$ is

$$
m^{\cdot} \text { hhe }=m^{\cdot} \text { or }+\frac{V \text { hhe }}{R T \text { hhe }} \frac{d p}{d \tau}
$$

The mass of gas hpt is the net mass remaining in the pulse tube after the flow of gas through orifice and is given as

$$
V_{h p t} \quad=\frac{m^{\cdot}{ }_{h p t} R T \quad h p t}{P}
$$

$M R$ in the system. With this new value of MR all the pressure values calculated from eqns. 3, 6 for each interval have to be multiplied so that $P_{\text {mean }}$ matches $P_{\text {avg }}$. The mass flow rates in each component of the system are calculated. The product of instantaneous pressures at each interval ' $q$ ' and the displaced volume of the cylinder and cpt part of the pulse tube volume will determine the net ideal work input and the refrigerating effect for 1 cycle. The input power and refrigeration effect is due to the working fluid displacement in cylinder and the cold part of pulse tube respectively.

$W=\oint P d V_{c y l} Q=\oint P d V_{c p t}$

The integration is carried out using trapezoidal rule. According to this rule the pressure $P$ is the average pressure of the interval point pressures. The above eqns.
Research article

CIndian Society for Education and Environment (iSee)
"Cryogenic refrigerators " http://www.indjst.org
Jayaraman \& Senthil Kumar Indian J.Sci.Technol. 
are multiplied with frequency to obtain the total work input and refrigerating effect.

Losses in PTR

The losses in an OPTR are due to:-

1. Incomplete thermal energy exchange between the fluid and matrix.

2. Frictional pressure drops in fluid.

3. Conduction loss in regenerator tube, pulse tube wall and matrix.

4. Temperature swing loss due to finite heat capacity of the regenerator.

5. Pressure drop through the pulse tube, precooler and HHE.

These are evaluated to obtain the actual cooling capacity of the OPTR. The increase in power requirement for the pulse tube refrigerator is due to pressure drop due to flow friction in the regenerator, precooler, $\mathrm{CHE}$, pulse tube and $\mathrm{HHE}$ sections and Mechanical Losses. The mathematical model is simulated in a computer program programmed in QUICK

BASIC, $\theta_{m}(n+1, i)=k_{1} \theta_{m}($ the flowcha $k_{3} \theta_{f}(n+1, i-1)+$ rt of

which is shown in Fig. 8.

Regenerator

The conflicting requirements for regeneration in an OPTR have been satisfied by selecting appropriate mesh material and size. A CFD analysis of mesh type regenerator in an OPTR for evaluating its performance is presented.

Regenerator simulation

$$
\theta_{f}(n+1, i)-B_{1} \theta_{f}
$$

To develop the mathematical model describing the exchange, the energy balance for the matrix material and working fluid in a control volume of the regenerator is established by employing the $1^{\text {st }}$ law of Thermodynamics, conservation of mass, momentum and heat transfer equation of fluid with matrix. To develop the mathematical model describing the exchange, the energy balance for the matrix material and

fluid in a small element or control volume of the regenerator is established by employing the $1^{\text {st }}$ law of Thermodynamics, conservation of mass, heat transfer equation and the equation of motion of fluid. The overall balance for the control volume is written in mathematical form and the energy balance for the fluid in the control volume is derived. The developed eqns. are complex, hence to obtain solutions the equations are simplified using suitable assumptions (Heggs, 1991) to obtain

$U \frac{\delta}{\delta z} T_{f}+\frac{d T_{m}}{d t}=0 \frac{\delta}{\delta z} T_{f}+\Lambda\left(T_{f}-T_{m}\right)=0$

The governing partial differential eqns. derived are non-dimensionalized, discretised and solved to predict the temperature distribution of working fluid and matrix along the length of the regenerator.

Research article

CIndian Society for Education and Environment (iSee)

"Cryogenic refrigerators" http://www.indjst.org
Vol. 3 No. 4 (Apr. 2010)

ISSN: 0974- 6846

\section{Numerical scheme}

The $\Lambda-\Pi$ technique in modified form is used to solve the differential equations by converting them to algebraic eqns. by the explicit form of finite difference technique (Heggs, 1991). The solution procedure starts with the non-dimensionalising the system of eqns. Normalised independent variables and temperatures are defined as follows:-

Normalised length $y=z / L$

Normalised period $\mathrm{q}=(\mathrm{t}-\mathrm{z} / \mathrm{u}) / \mathrm{P}$

Normalised temperature $\theta(y, q)=T_{j}(y, q)-T_{2, i n}$

I $\left(T_{1, \text { in }}-T_{2, \text { in }}\right)$, where $\mathrm{j}=1,2, \mathrm{~m}$

After normalising, Eqn. 9 becomes

$U \frac{\partial \theta}{\partial y}+\frac{d \theta_{m}}{d q}=0 \frac{\partial \theta_{f}}{\partial y}+\Lambda\left(\theta_{f}-\theta_{m}\right)=0$

The time and length derivative in the first normalised Eqn. 10 is replaced by a central difference approximation about nodal point $(n+1 / 2$, i) to obtain the following algebraic equations (Heggs, 1991). $(n+1, i-1)+k_{2} \theta_{m}(n, i)+$

${ }_{4} \theta_{f}(n, i)=0 \quad-11$

where

$A 1=2-\wedge U . q /(2+\wedge U . q)$ and $A_{2}=\wedge U . q /(2+\wedge U . q)$.

The $2^{\text {nd }}$ eqn. i.e. the fluid balance eqn. 10 is converted into an algebraic equation by replacing the length derivative by a central difference derivative approximation about the nodal points $(\mathrm{n}+1, \mathrm{i}-1 / 2)$ to give

$(n+1, i-1)-B_{2}\left(\theta_{m}(n+1, i)+\theta_{m}(n+1, i-1)\right)=0_{-12}$

where $B 1=2-\Lambda . y /(2+\Lambda . y)$ and $B_{2}=\Lambda . y /(2+\Lambda . y)$. The matrix temperature is obtained from substituting Eqn. 12 in Eqn.11 to give (Heggs, 1991)

$\theta_{m}(n+1, i)-A_{1} \theta_{m}(n, i)-A_{2}\left(\theta_{f}(n+1, i)+\theta_{f}(n, i)\right)=0$

where $\mathrm{k} 1=\mathrm{A}_{1} /\left(1-\mathrm{A}_{2} \mathrm{~B}_{2}\right) ; \mathrm{k}_{2}=\mathrm{A}_{2} \mathrm{~B}_{2} /\left(1-\mathrm{A}_{2} \mathrm{~B}_{2}\right)$; $k_{3}=A_{2} B_{1} /\left(1-A_{2} B_{2}\right)$ and $k_{4}=A_{2} /\left(1-A_{2} B_{2}\right)$. The boundary conditions for the hot period and the cold period are specified. It is normalised and applied for the solution of the eqns. A linear distribution of temperature is imposed upon the matrix. Subsequently the temperatures at the end of successive periods are evaluated repeatedly until the mathematic model achieves cyclic equilibrium. The algebraic eqns. are used in the simulation program of a regenerator.

\section{Solution procedure}

The numerical solution procedure is as given below:

a. Dimensionless time and space coordinates $z$ and $q$ are represented by a system of nodal points on a mesh arrangement of size $\mathrm{z}$ and $\mathrm{q}$. Each nodal point may be signified by the notation $(n, i)$ where $n=$ time step and $i=$ length step. The number of time and length step depends on the stability criteria. The 
numerical solution will find both gas and solid temperatures at each nodal point in the mesh covering the time and space domain.

b. The pulse tube refrigerator system configuration and its operating conditions are specified.

c. The boundary conditions of the regenerator is assigned

d. The empirical formulae of heat transfer and fluid flow friction factors are applied for a particular node with the fluid and matrix properties taken for temperature at that node.

e. The temperature of matrix and fluid at each node is calculated after 1 time step given the condition at the beginning of that time step. At any given instant having known the temperatures at $(2,1),(1,1),(1,2)$ the temperature at 2,2 can be found.

$f$. Step ' $e$ ' is continued for the entire length of the regenerator till the final time step for the compression half cycle or the hot cycle.

g. The process is repeated for the cold period of the cycle. The temperature profile at the end of the hot period is taken as the profile at the beginning of the cold period. The constant for Eqn. 9 is changed to account for the unbalance factor and non symmetry factor.

h. The time step calculations are continued for several cycles of flow of fluid until quasi steady state is reached, when the difference in temperature at each node between 2 cycles is less than a given tolerance. Convergence to cyclic equilibrium is checked after the evaluation of a complete cycle.

i. The effectiveness and losses in the regenerator is calculated. The losses are given in detail in the next section. The effectiveness is given by the dimensionless fluid temperature at the exit of the matrix

$$
\varepsilon=\frac{T_{\text {g.h.out }}-T_{\text {g.h.in }}}{T_{\text {g.h.in }}-T_{\text {g.c.in }}}
$$

j. The temperature profile and performance parameters for given input conditions are printed for the regenerator. Losses in a regenerator Losses in the regenerator influence the performance by increasing the net power input and decreasing the refrigerating capacity of the system. The decrease in refrigeration capacity is due to regenerator ineffectiveness, irrecoverable pressure, drop longitudinal conduction through the matrix, regenerator tube. The following correlations are compiled from the literature based on system similarity and computational ease. Fluid flow in the regenerator of a PTR is accompanied by significant pressure change. The irrecoverable pressure drop through a regenerator matrix is obtained from

$$
\Delta P=n_{m} f(1 / 2) v_{r}^{2} \rho
$$

$$
---15
$$

"Cryogenic refrigerators" http://www.indjst.org $v_{r}$ is the mean velocity of the fluid flowing through the regenerator with density $\rho$ through the regenerator and $n_{m}$ is the number of mesh punching $\mathrm{n}$ the regenerator. ' $\mathrm{f}$ ' is the friction factor obtained from experimental pressure drop data for steady unidirectional flow through screen matrices where $\mathrm{N}_{\mathrm{re}}$ is the Reynolds number.

$$
f=\frac{33.6}{N_{\mathrm{Re}}}+0.337
$$

The longitudinal conduction through the regenerator holding tube is

$Q_{c t}=k_{t} A_{t}\left(T_{h}-T_{c}\right)(1-\varepsilon)$

A similar eqn. calculates the longitudinal conduction loss in the pulse tube wall. Similarly the longitudinal heat transfer along the regenerator matrix is

$Q_{c r m}=\frac{k_{e q} A_{e q}\left(T_{h}-T_{c}\right)}{L_{t}}$

The equivalent longitudinal thermal conductivity of the matrix $k_{\text {eq }}$ depends on the method of stacking and on the contact resistance between adjacent stacks. Martini has used the Gorring eqn. which does not take into account the contact resistance.

$$
k_{e q}=k_{f} \frac{\left(1+\frac{k_{m}}{k_{f}}\right)-f f\left(1-\frac{k_{m}}{k_{f}}\right)}{\left(1+\frac{k_{m}}{k_{f}}\right)+f f\left(1-\frac{k_{m}}{k_{f}}\right)}
$$

Where $\mathrm{ff}$ is the fill factor, the fraction of regen erator volume filled with solid. $k_{m}$ and $k_{f}$ are the thermal conductivities of the matrix and the fluid. The equivalent cross sectional area for the heat conduction transfer is

$$
A_{e q}=F(1-p o r) A_{r}
$$

The reheat loss associated with the ineffectiveness of the regenerator. Owing to the incomplete heat exchange between the gas stream and regenerator matrix, gas will arrive at the cold end at a higher temperature than the cold end matrix temperature during the inlet process. It is given by

$$
Q_{r . i}=m c_{v}\left(T_{h}-T_{c}\right)(1-\varepsilon)_{--21}
$$

The equations derived for giving the variation in the fluid and matrix material properties as function of pressure and temperature is included in the calculation of pressure drop and heat transfer coefficients at each node along the regenerator in the numerical solution. The flowchart of the simulation of regenerator, developed as a computer program is given in Fig. 9. This program is integrated with the PTR system program to simulate an actual OPTR. An optimum regenerator is one for which the combined losses due hydrodynamic pumping and imperfect heat exchange at given operating conditions are a minimum. This optimum regenerator would have a continuous variation in hydraulic diameter (Andeen, 1982).
Research article

CIndian Society for Education and Environment (iSee)
Jayaraman \& Senthil Kumar Indian J.Sci.Technol. 
Fig. 1. Schematic of an Orifice type Pulse Tube Refrigerator

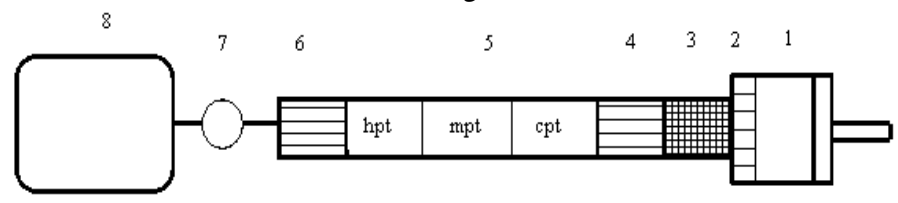

1-Compressor; 2-After cooler; 3-Regenerator; 4-Cold Heat Exchanger; 5-Pulse Tube; 6-Hot Heat Exchanger; 7-Orifice; 8-Reservoir
Vol. 3 No. 4 (Apr. 2010)

ISSN: 0974- 6846

Fig. 2. Pressure variations in the system \& Compressor volume variations for one cycle

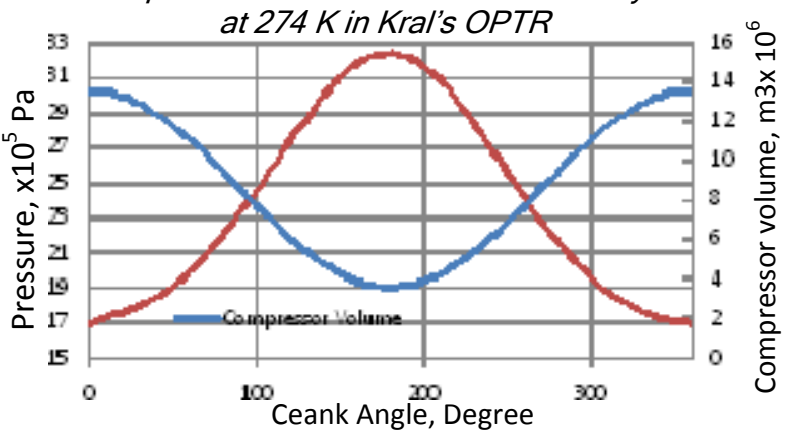

Table 1. Configuration of OPTR input to the Simulation program

\begin{tabular}{|c|c|c|}
\hline Component & Kral et al. (1992) & Huang \& Yu (2001) \\
\hline After Cooler & $1.27 \mathrm{~cm} \mathrm{ID,} 1.27 \mathrm{~cm}$ length & Diameter $=3 \mathrm{~mm}$; length $=100 \mathrm{~mm}$ \\
\hline Regenerator, SS & $\begin{array}{l}1.27 \mathrm{~cm} \text { OD, } 1.17 \mathrm{~cm} \mathrm{ID,} 10.3 \mathrm{~cm} \text { length, filled with } 1075 \text { nos. } 400 \\
\text { mesh SS316 }\end{array}$ & $\begin{array}{l}9.3 \mathrm{~mm} \text { OD, } 9 \mathrm{~mm} \text { ID, } 110 \mathrm{~mm} \text { long, } 400 \text { mesh-180 } \\
\text { disks; } 200 \text { mesh-700 disks; } 150 \text { mesh-400disks }\end{array}$ \\
\hline $\begin{array}{l}\text { Cold Heat } \\
\text { Exchanger }\end{array}$ & $\begin{array}{l}0.826 \mathrm{~cm} \text { ID, } 1.52 \mathrm{~cm} \text { length, filled with } 40 \text { numbers } 100 \text { mesh } \\
\text { copper screen discs, resistance wire wound heater for cooling load }\end{array}$ & $\begin{array}{l}\text { Cold-end exchanger (screen mesh/no. } \\
\text { disks/length):100/20/30mm; diameter-2 mm }\end{array}$ \\
\hline Pulse Tube & S.S. $316,0.794 \mathrm{~cm}$ OD, $0.743 \mathrm{~cm} \mathrm{ID,} 5.08 \mathrm{~cm}$ length & $8.9 \mathrm{~mm}$ ID, $90 \mathrm{~mm}$ Length \\
\hline Orifice & Whitey valve SS-22RS4 with vernier handle; Area $0.32 \mathrm{~mm}^{2}$ & Needle Valve SS-22RS2; Area $0.142 \mathrm{~mm}^{2}$ \\
\hline Ballast & Diameter $5.08 \mathrm{~cm} ; 21.1 \mathrm{~cm}$ length & $80 \mathrm{~cm}^{3}$ \\
\hline Refrigerant & Helium & Helium \\
\hline $\begin{array}{l}\text { Operating } \\
\text { Parameters }\end{array}$ & $\begin{array}{l}\text { Charge Pressure }-17.5 \mathrm{~kg} / \mathrm{cm}^{2} \text {; } \\
\text { Frequency }-13 \mathrm{~Hz} \text {. }\end{array}$ & $\begin{array}{l}\text { Charge Pressure - } 15 \text { bar; } \\
\text { Frequency }-7 \mathrm{~Hz} \text {. }\end{array}$ \\
\hline
\end{tabular}

Table 2. Performance arameters redicted at varying $T_{\text {cold end }}$ for an OPTR using the configuration of Kral et al. (1992)

\begin{tabular}{|c|c|c|c|c|}
\hline \multirow[b]{2}{*}{$\begin{array}{l}\text { Cold end } \\
\text { Temp. K }\end{array}$} & \multicolumn{3}{|c|}{ Predicted Results } & \multirow[b]{2}{*}{$\begin{array}{c}\text { Kral's Expt., } \\
\text { W }\end{array}$} \\
\hline & $\begin{array}{c}\text { Q efrigeration, }_{\text {W }} \\
\text {, }\end{array}$ & $\begin{array}{c}Q_{\text {loss }}, \\
W\end{array}$ & $\begin{array}{c}\text { Qactual, } \\
\text { W }\end{array}$ & \\
\hline 90 & 1.543 & 6.993 & -5.45 & 0 \\
\hline 102 & 6.431 & 4.722 & 1.709 & 1 \\
\hline 115 & 6.644 & 4.172 & 2.472 & 2 \\
\hline 162 & 8.591 & 2.641 & 5.859 & 5 \\
\hline 185.7 & 9.188 & 0.777 & 8.411 & 7.76 \\
\hline 227.14 & 11.527 & 0.345 & 11.182 & 10.13 \\
\hline 240 & 11.87 & 0.291 & 11.579 & 10.6 \\
\hline 274 & 12.837 & 0.147 & 12.689 & 11.57 \\
\hline
\end{tabular}

Fig. 3. P-V diagram for expansion of cpt volume at 274 K of Kral's OPTR

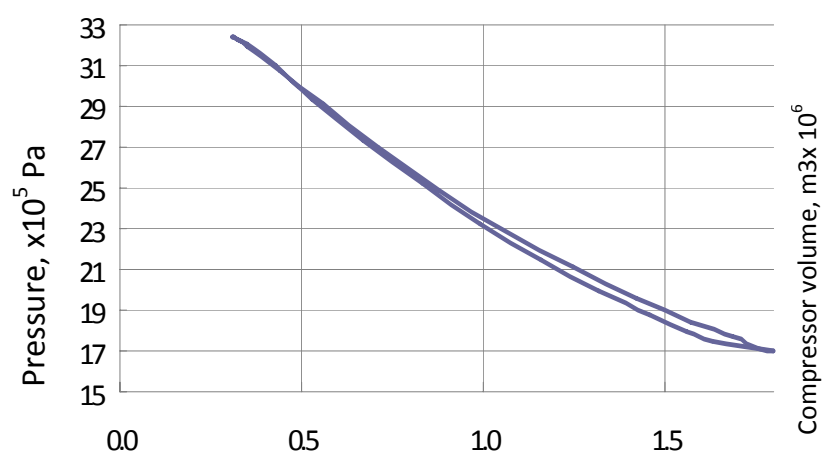

Research article

CIndian Society for Education and Environment (iSee)
Table 3. Performance parameters predicted at varying $T_{\text {cold end }}$ for an OPTR using configuration of Huang \& Yu(2001)

\begin{tabular}{|c|c|c|c|c|}
\hline \multirow[b]{2}{*}{$\begin{array}{l}\text { Cold end } \\
\text { Temp. K }\end{array}$} & \multicolumn{3}{|c|}{ Predicted Results } & \multirow{2}{*}{$\begin{array}{c}\text { Huang } \\
\text { \& Yu Expt.,W }\end{array}$} \\
\hline & $\begin{array}{c}\text { Qrefrigeration, } \\
\text { W }\end{array}$ & $\begin{array}{c}\text { Qloss, } \\
\text { W }\end{array}$ & $\begin{array}{c}\text { Qactual, } \\
\text { W }\end{array}$ & \\
\hline 95 & 6.346 & 5.822 & 0.524 & 0 \\
\hline 101 & 6.549 & 5.742 & 0.807 & 0.5 \\
\hline 109 & 6.938 & 5.565 & 1.373 & 1 \\
\hline 118 & 6.965 & 5.366 & 1.599 & 1.5 \\
\hline 125 & 7.274 & 5.175 & 2.98 & 2 \\
\hline 132 & 7.534 & 5.020 & 2.514 & 2.5 \\
\hline 139 & 8.214 & 4.837 & 3.378 & 3 \\
\hline 95 & 6.346 & 5.822 & 0.524 & 0 \\
\hline
\end{tabular}

Fig. 4. Predicted performance compared with the published experimental results of Kral's OPTR (Kral et al., 1992)

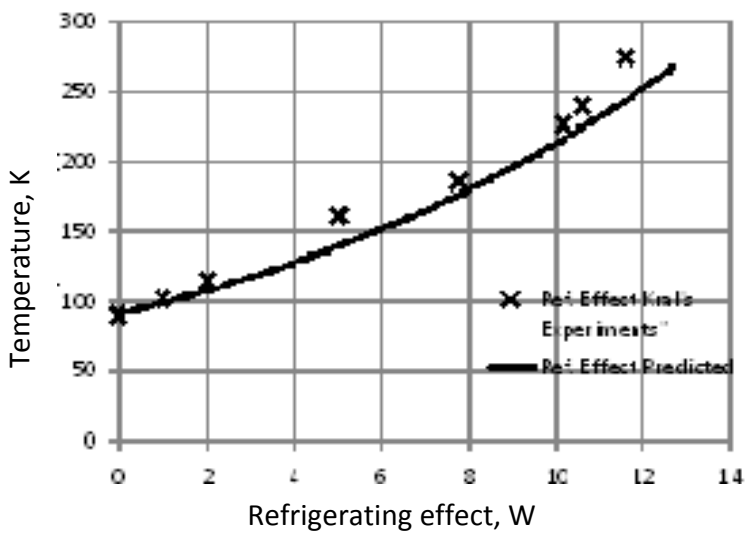

Jayaraman \& Senthil Kumar Indian J.Sci.Technol. 
Fig. 5. Predicted performance compared with the published experimental results of OPTR of Huang \& Yu (2001)

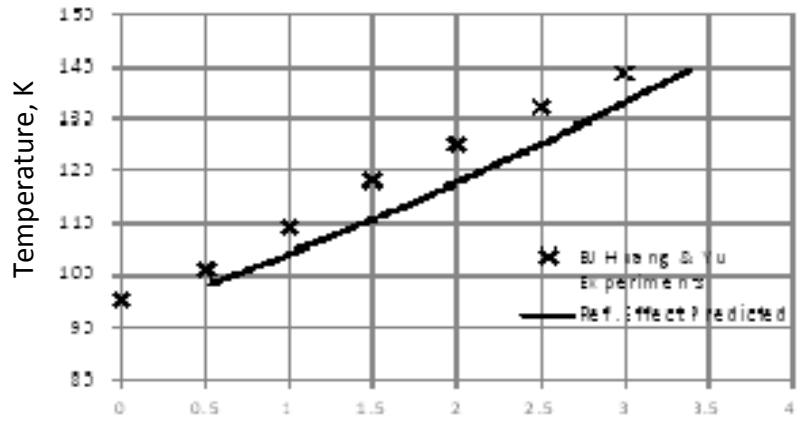

Fig. 6. Performance along 400 Mesh Regenerator of OPTR of Kral et al.(1992)

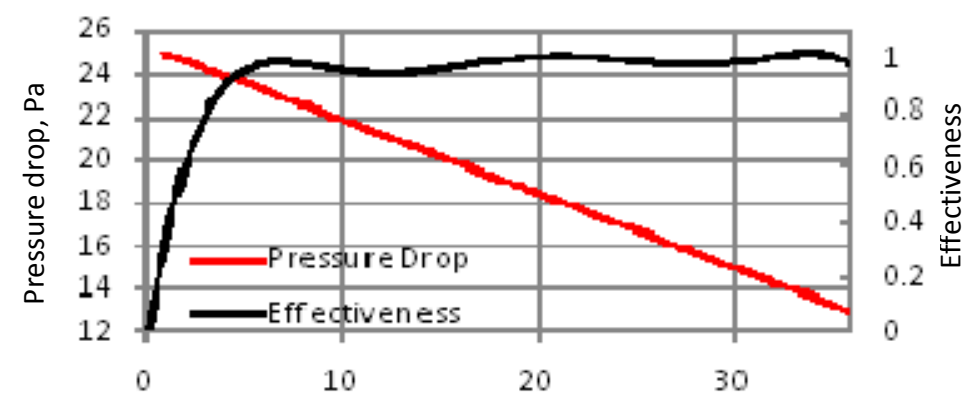

Nodal length of Regenerator

Fig. 7. Performance along nodal length of 250-300-400 Mesh Hybrid Regenerator

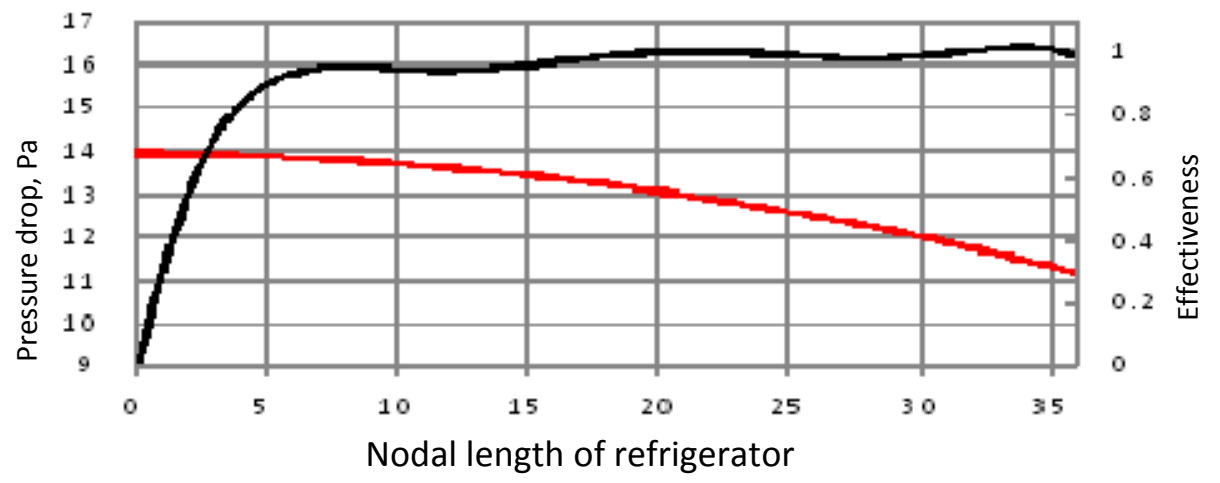

Table 4. Regenerator Performance predicted for the 150-200-400 mesh combination for an OPTR using the configuration of Huang and Yu.(2001)

\begin{tabular}{|l|c|c|}
\hline \multicolumn{1}{l|}{ the configuration of Huang and Yu.(2001) } \\
\hline & $\begin{array}{c}\text { Actual stacked } \\
\text { length }\end{array}$ & $\begin{array}{c}\text { Theoretical } \\
\text { stacked length }\end{array}$ \\
\hline $\begin{array}{l}\text { Mesh Length } \\
\text { in mm: }\end{array}$ & $40.64-56.84-9.144$ & $\begin{array}{c}44.01-56 . \\
84-9.144\end{array}$ \\
\hline Total Length: & $106.64 \mathrm{~mm}$ & $110 \mathrm{~mm}$ \\
\hline Effectiveness: & 0.4115 & 0.4214 \\
\hline Pressure Drop: & $0.117997 \mathrm{bar}$ & $0.11670 \mathrm{bar}$ \\
\hline $\begin{array}{l}\text { Refrigerating } \\
\text { Effect in the } \\
\text { Refrigerator }\end{array}$ & $0.524 \mathrm{~W}$ & $0.744 \mathrm{~W}$ \\
\hline
\end{tabular}

Table 5. Performance of Hybrid Regenerator Combination in Huang and Yu's OPTR

\begin{tabular}{|l|c|c|c|c|}
\hline \multicolumn{6}{|c|}{ Combination in Huang and Yu's OPTR } \\
\hline $\begin{array}{l}\text { Combination } \\
\text { Length (mm) }\end{array}$ & $\begin{array}{c}10 / 70.14 \\
150-200-400\end{array}$ & $\begin{array}{c}20 / 57.74 \\
/ 29.84 / 27.98\end{array}$ & $\begin{array}{c}60 / 8.14 \\
/ 32.25\end{array}$ \\
\hline Effectiveness & 0.4278 & 0.4269 & 0.4160 & 0.4024 \\
\hline $\begin{array}{l}\text { Pressure } \\
\text { drop, bar }\end{array}$ & 0.14725 & 0.15051 & 0.15135 & 0.15361 \\
\hline $\begin{array}{l}\text { Refrigerating } \\
\text { Effect, W }\end{array}$ & 0.973 & 0.979 & 0.911 & 0.759 \\
\hline
\end{tabular}

Research article

(C) Indian Society for Education and Environment (iSee)
Table 6. 400 Mesh Regenerator Performance predicted by the computer program

\begin{tabular}{|c|c|}
\hline $\begin{array}{c}\text { Input } \\
\text { Conditions }\end{array}$ & $\begin{array}{l}\text { Performance } \\
\text { parameters }\end{array}$ \\
\hline $\begin{array}{l}\text { Cold End } \\
\text { Temp. } 80 \mathrm{~K}\end{array}$ & $\begin{array}{l}\text { Effectiveness } \\
0.9907\end{array}$ \\
\hline $\begin{array}{l}\text { Warm end } \\
\text { Temp. } \\
293 \mathrm{~K}\end{array}$ & $\begin{array}{l}\text { Conduction } \\
\text { loss in } \\
\text { Matrix } 0.0129 \mathrm{~W}\end{array}$ \\
\hline $\begin{array}{l}\text { Charge } \\
\text { Pressure } \\
16.5 \text { bar }\end{array}$ & $\begin{array}{l}\text { Conduction } \\
\text { Loss } \\
\text { Regenerator } \\
\text { tube } 0.478 \mathrm{~W}\end{array}$ \\
\hline $\begin{array}{l}\text { Length of } \\
\text { Regenerator } \\
103 \mathrm{~mm}\end{array}$ & $\begin{array}{l}\text { Conduction } \\
\text { loss in Pulse } \\
\text { tube } 0.312 \mathrm{~W}\end{array}$ \\
\hline $\begin{array}{l}\text { Mesh size } \\
400 \text { Mesh }\end{array}$ & $\begin{array}{l}\text { Reheat loss in } \\
\text { Matrix } 0.0286 \mathrm{~W}\end{array}$ \\
\hline $\begin{array}{l}\text { Diameter of } \\
\text { Regenerator } \\
11.7 \mathrm{~mm}\end{array}$ & $\begin{array}{l}\text { Pressure drop } \\
\text { during } \\
\text { Compression } \\
0.1268 \text { bar }\end{array}$ \\
\hline $\begin{array}{l}\text { Material } \\
\text { Stainless } \\
\text { Steel }\end{array}$ & $\begin{array}{l}\text { Expansion } \\
0.1699 \text { bar }\end{array}$ \\
\hline
\end{tabular}

"Cryogenic refrigerators " http://www.indjst.org
Table 7. Hybrid Regenerator Performance predicted by the computer program

\begin{tabular}{|c|c|}
\hline $\begin{array}{c}\text { Input } \\
\text { Conditions }\end{array}$ & $\begin{array}{l}\text { Performance } \\
\text { parameters }\end{array}$ \\
\hline $\begin{array}{l}\text { Cold End } \\
\text { Temp. } 80 \mathrm{~K}\end{array}$ & $\begin{array}{l}\text { Effectiveness } \\
0.9923\end{array}$ \\
\hline $\begin{array}{l}\text { Warm end } \\
\text { Temp. } 293 \mathrm{~K}\end{array}$ & $\begin{array}{l}\text { Conduction } \\
\text { loss in Matrix } \\
0.019 \mathrm{~W}\end{array}$ \\
\hline $\begin{array}{l}\text { Charge } \\
\text { Pressure } \\
16.5 \text { bar }\end{array}$ & $\begin{array}{l}\text { Conduction Loss, } \\
\text { regenerator tube } \\
0.478 \mathrm{~W}\end{array}$ \\
\hline $\begin{array}{l}\text { Length of } \\
\text { Regenerator } \\
103 \mathrm{~mm}\end{array}$ & $\begin{array}{l}\text { Conduction loss, } \\
\text { Pulse tube } \\
0.311 \mathrm{~W}\end{array}$ \\
\hline $\begin{array}{l}\text { Mesh size } \\
250-300-400 \\
\text { Mesh }\end{array}$ & $\begin{array}{l}\text { Reheat loss in } \\
\text { Matrix } 0.028 \mathrm{~W}\end{array}$ \\
\hline $\begin{array}{l}\text { Diameter of } \\
\text { Regenerator } \\
11.7 \mathrm{~mm}\end{array}$ & $\begin{array}{l}\text { Pressure drop } \\
\text { during } \\
\text { Compression } \\
0.0897 \text { bar }\end{array}$ \\
\hline $\begin{array}{l}\text { Material } \\
\text { Stainless } \\
\text { Steel }\end{array}$ & $\begin{array}{l}\text { Expansion } \\
0.1172 \text { bar }\end{array}$ \\
\hline
\end{tabular}

Jayaraman \& Senthil Kumar Indian J.Sci.Technol. 


\section{Hybrid regenerator}

Based on empirical understanding the hydraulic radius of mesh called a Hybrid regenerator has been varied along the stack length and improved performances have been reported (Andeen, 1982). The design principle and optimisation for a hybrid regenerator in an OPTR is also discussed. The hybrid regenerator concept is analyzed and a computer coded search is carried out. The unconstrained optimization technique of iterative trial solution proceeding towards optimum point in a sequential manner is adopted. The length of mesh size combination having a minimum of total losses is selected in an iterative process.

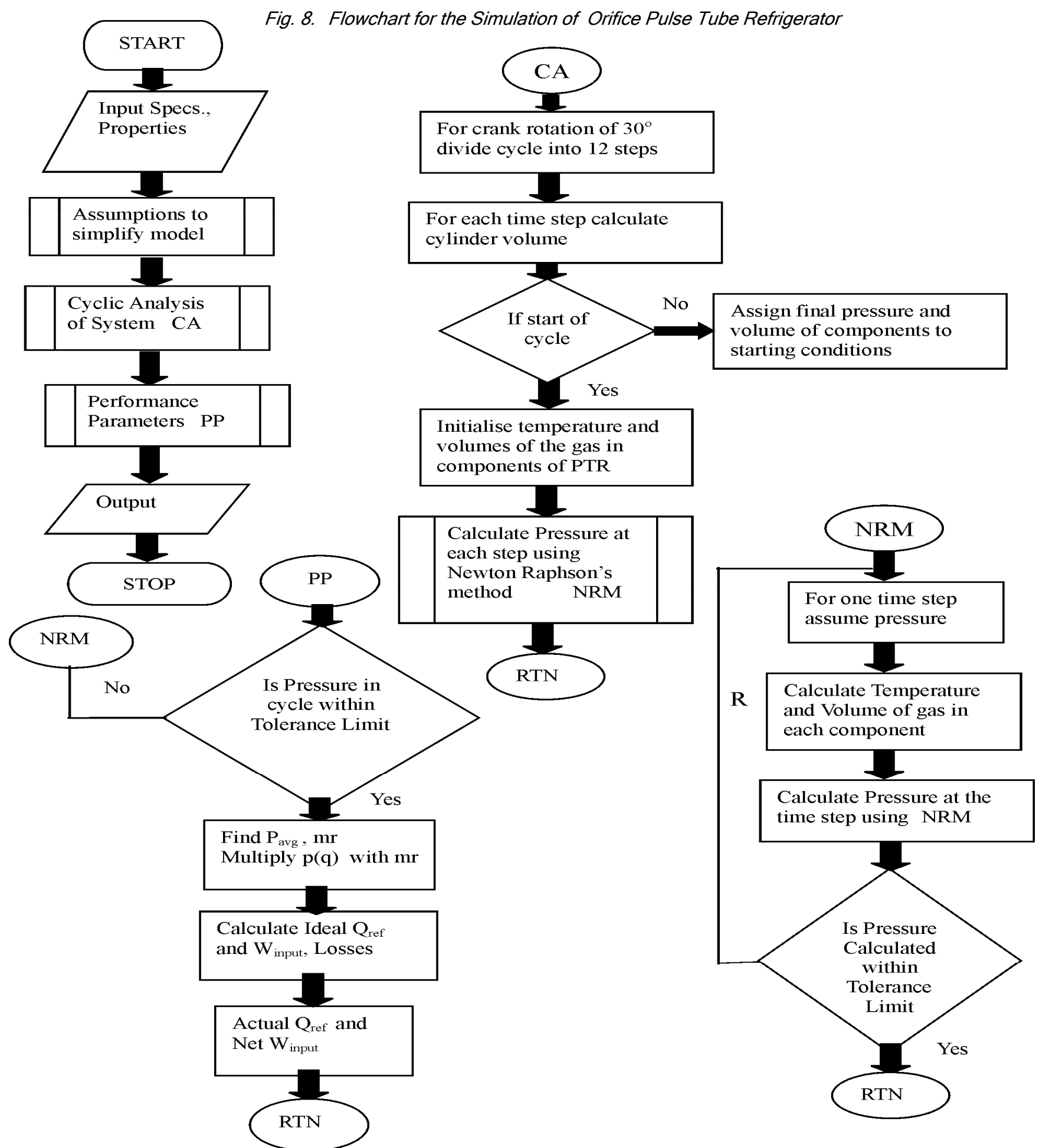




\section{Optimisation}

It is the process of finding the conditions that give the maximum or minimum value of a function called the objective function. The objective functions in the present case are minimum pressure drop of the fluid flowing through the regenerator and maximum effectiveness of the regenerator. The objective functions are controlled by the geometrical factors and material of the regenerator matrix. The geometric factors of the matrix are the mesh size and volume of the respective size matrix which in combination can give the maximum effectiveness and simultaneously a minimum pressure drop. Many volume and thereby length combinations for a given area of mesh sizes are possible and a methodology is proposed to generate the length of mesh combinations confirming to the physical and geometrical constraints.

\section{Fig. 9. Flowchart for the simulation program of single mesh} regenerator
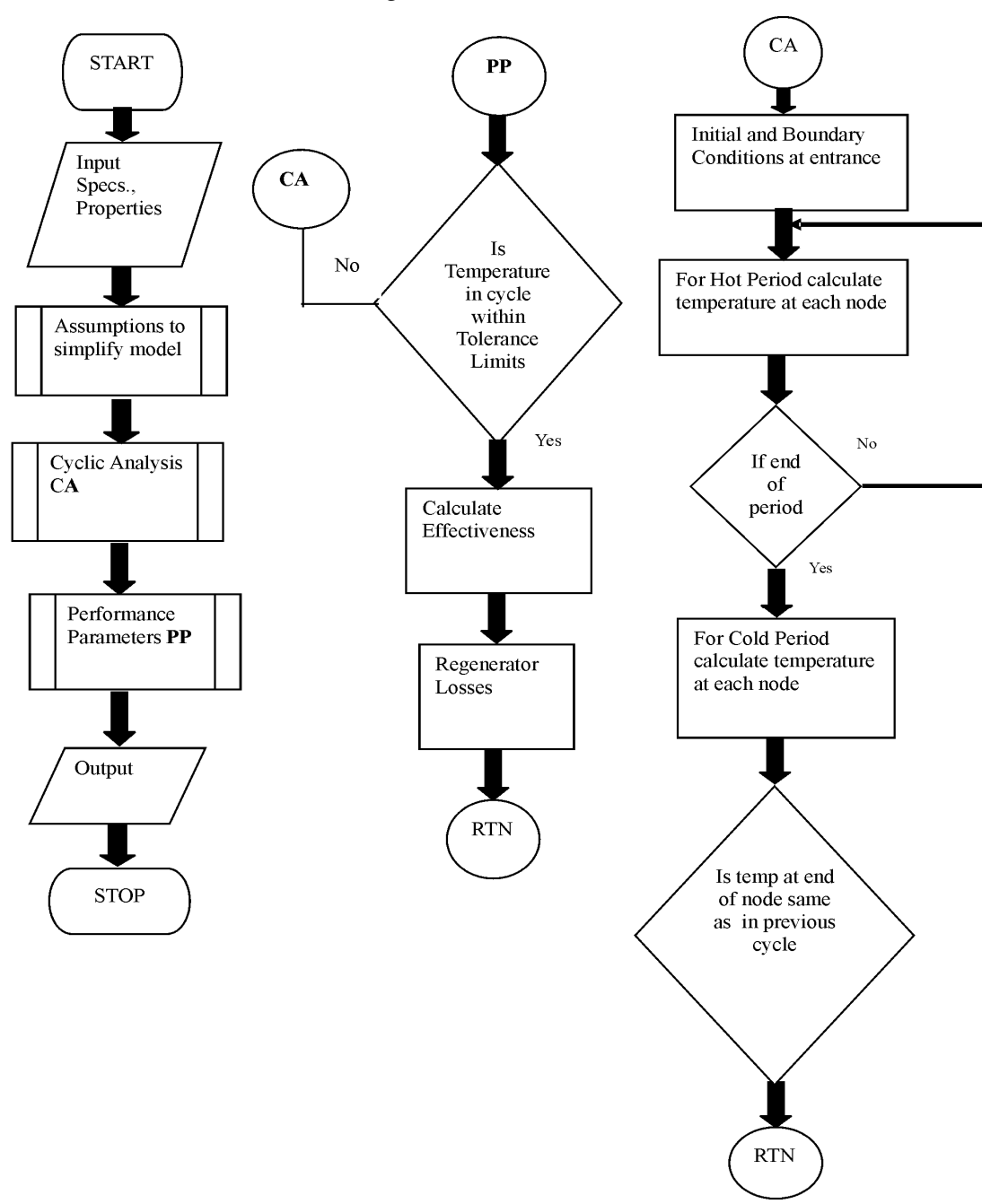

sizes. Also, if 3 mesh size zones are taken to constitute the regenerator, then the meshes have to be suitably arranged within the regenerator space in the system. The commonly available mesh sizes in the market and which satisfy the heat transfer between the fluid and matrix are $150,200,250,300$ and 400 . Each of these mesh sizes have 2 or 3 types of wire diameters. Thus the selection of combination of mesh size and wire diameter for complete heat transfer between fluid and matrix has a large number of possibilities. As there is no constraint over the regenerator mesh geometry, the optimisation problem can be solved through unconstrained optimisation technique. This method is iterative in nature and starts with a trial solution and proceeds towards the optimum point in a sequential manner. The search for an optimum point may be a direct search method or descent method.

Descent techniques require in addition to an objective function, the derivatives of the function. As the dependent variables in the geometry of the regenerator are many for a given independent variable, the descent method will lead to mathematical complexity. Hence a direct search method is adopted in the present work. In the direct search method, the univariate method of search, wherein 1 variable is changed at a time and a sequence of improved performance are sought to arrive at the optimum point. As the function to be optimised, minimum pressure drop and maximum effectiveness of regenerator are not a directly available function in terms of the mesh size, mesh wire diameter and volume to be optimised, other methods of optimisation cannot be applied.

Hence the optimisation method adopted in the present analysis is the univariate method of search in the unconstrained optimisation technique. 3 mesh size zones are taken to constitute the regenerator volume and the meshes are to be suitably arranged within the regenerator. The design methodology for the 3 zone matrix is as follows:-

a. Total Length of the regenerator

$\mathrm{L}_{1}+\mathrm{L}_{2}+\mathrm{L}_{3}=\mathrm{tl}$ $---12$

where $L_{1}, L_{2}$, and $L_{3}$ are the individual lengths of the 3 meshes.

b. Volume of the Regenerator meshes

The regenerator void volume of the meshes should be equal to the total regenerator void volume.

$\mathrm{V}_{\mathrm{r} 1}+\mathrm{V}_{\mathrm{r} 2}+\mathrm{V}_{\mathrm{r} 3}=\mathrm{V}_{\mathrm{r}}$ and por $\mathrm{L}_{1}+$ por $_{2} \mathrm{~L}_{2}+$ por $_{3} \mathrm{~L}_{3}=$ $V_{r} / A_{r}$

The void volume of the regenerator $V_{r}$, total length of the regenerator $t 1$, regenerator frontal

\section{Optimisation technique}

The losses in refrigeration capacity and work done are dependent on the pressure drop through the regenerator volume. A given regenerator volume can be obtained from numerous length combinations of mesh
Research article

CIndian Society for Education and Environment (iSee)
"Cryogenic refrigerators " http://www.indjst.org
Jayaraman \& Senthil Kumar Indian J.Sci.Technol. area $A_{r}$ are design parameters obtained from the system optimisation. As there are 3 unknowns and 2 eqns., 1 unknown $L_{1}$ is assumed and the other $2 L_{2}$ and $L_{3}$ are calculated. 
c. Equations are written in matrix form $A X=C$, where $A$ is the coefficient matrix, $X$ is the unknown matrix and $C$ is the constant matrix. The solution of $X$ is obtained by Cramer's rule $X=A^{-1} C$. $A^{-1}$ is the inverse of matrix $A$ and is obtained by Gauss Jordon rule.

\section{Results}

Configuration of orifice pulse tube refrigerators published in the open literature along with their experimental results is taken as reference and input into the simulation program. The performances of the OPTR's predicted by the program are compared with the published experimental results for validation.

\section{Pulse tube refrigerator}

The specifications of OPTR developed by Kral (Kral et al., 1992) and Huang (Huang \& Yu, 2001) are given in Table 1. These specifications are input into the computer program and performance parameters are predicted. The pressure variations, given in eqn. 7 , in the system during each step of the $360^{\circ}$ crank rotation in the cycle based on the assumed volume variations given in eqn. 1 of the fluid in the cylinder is shown in Fig. 2. The refrigeration effect due to the working fluid displacement in the cold part of pulse tube as given in eqn. 8 for $274 \mathrm{~K}$ cold heat exchanger temperature is shown in Fig. 3. The area of the $P-V_{\text {cpt }}$ diagram gives the ideal refrigeration effect for 1 cycle. This is multiplied with frequency to give the gross refrigeration effect. The losses in the OPTR system, enumerated are calculated and deducted fro the gross refrigerating effect to obtain the actual refrigeration effect and listed in Table 2 for each CHE temperature. The performance parameters with Kral's experimental setup configuration as input, for various cold end temperatures are given in Table 2 . The predicted refrigerating effect drawn as a polynomial is compared with experimental results of Kral (Kral et al., 1992) and shown in Fig. 4. At $274 \mathrm{~K}$ the refrigerating effect of the program is $12.689 \mathrm{~W}$, whereas the actual experimental result is $11.57 \mathrm{~W}$, a difference of $8.5 \%$.

Similarly, an OPTR developed by Huang (Huang and $\mathrm{Yu}, 2001$ ) is given in $3^{\text {rd }}$ column of Table 1 and input into the simulation program to validate the mathematical model developed. The output of the program for various cold end temperatures is given in Table 3 . The predicted refrigerating effect, drawn as a polynomial is compared with experimental results of Huang (Huang and $\mathrm{Yu}, 2001$ ) is shown in Fig. 5. At $139 \mathrm{~K}$ the refrigerating effect predicted by the program is $3.378 \mathrm{~W}$, whereas the actual experimental result is $3 \mathrm{~W}$, a difference of $11.2 \%$. As the difference between the predicted and actual experimental results is less than $12 \%$, the program is validated. Hence, the program developed based on the model described will be used in optimizing in existing systems and developing new OPTR for a given application.

\section{Regenerator performance}

The regenerator meshes in the OPTR's of Huang (Huang and Yu, 2001) and Kral (Kral et al., 1992) are analysed for its performance and losses behaviour.
Huang and Yu OPTR: The regenerator mesh combination of 150,200 and 400 mesh size is stacked 1 over the other in the regenerator tube. The length of the Regenerator tube is $110 \mathrm{~mm}$ whereas the actual geometric length of the meshes that has been stacked in the experimental set up is $106.6 \mathrm{~mm}$. This is due to incomplete packing of the meshes, due to contact resistance between adjacent stacks called the packing factor. Its performance is calculated and shown in Table 4. If the tube was filled with all the meshes without taking into account the contact resistance the geometric length increases to $44.01 \mathrm{~mm}$ for the 150 mesh regenerator and its effectiveness increases by $2.5 \%$, thereby increasing its refrigerating effect by $42 \%$, due to reduced dead space. It can also be inferred that there would be an optimum combination of the lengths of 150,200 and 400 mesh combination which would give a maximum refrigerating effect and minimum pressure drop. Hence the lengths of the 150 mesh in the 150-200-400 mesh combination regenerator in Huang and Yu's Orifice PTR is varied from lengths of $10 \mathrm{~mm}$ to $60 \mathrm{~mm}$ keeping the constraints as given in eqns. 12 and 13 . The performance of the Orifice PTR and regenerator in particular is calculated and tabulated in Table 5. It is seen that a maximum refrigerating effect of the OPTR is obtained with the 20/57/74/32.25 mm lengths of the 150-200-400 mesh size combination. Even though the 10/70.14/29.85 mesh gives a higher effectiveness and a lower pressure drop, the higher losses due to conduction and reheat loss leads to lower Refrigeration Effect. To further investigate and analyse the hybrid regenerator, the following section investigates the performance if a hybrid regenerator is placed in the regenerator tube of Kral (Kral et al., 1992).

Kral's OPTR: Performances are calculated for the single mesh regenerator in OPTR configuration of Kral. The performance parameters predicted by the program for given input conditions are given in Table 6.The loss due to pressure drop of the flowing fluid and effectiveness at a particular time step, along the length of regenerator with the hot end entry at the left and cold end at right is plotted in Fig. 6. The pressure drop term is large at the warm end and effectiveness term is high at the cold end. The effectiveness is primarily a function of the matrix element size. Larger mesh number regenerators give higher effectiveness, but the flow losses increase proportionately. The performance parameters for the same input conditions are compared with the method of analysis of Ackerman (Thirumaleshwar \& Subramanyam, 1986). The effectiveness obtained by this method is 0.99632, thus validating the computer program developed. The losses occurring in the 400 Mesh regenerator of the given OPTR is plotted for a particular time step in Fig. 4. Based on the discussions of combination of mesh sizes performance given in section 5.1 , an optimal mesh combination giving a maximum effectiveness and minimum pressure drop for hybrid regenerator is obtained when the single mesh
Research article

CIndian Society for Education and Environment (iSee)
"Cryogenic refrigerators " http://www.indjst.org
Jayaraman \& Senthil Kumar Indian J.Sci.Technol. 
regenerator is replaced by inserting a hybrid regenerator in the Kral's OPTR system.

\section{Hybrid regenerator}

The performance with the length of 250 Mesh size varying from $10 \mathrm{~mm}$ to $80 \mathrm{~mm}$ in the combination is tabulated in Table 8. Lengths for 250-300-400 mesh combinations are calculated and performance predicted for each combination. The maximum effectiveness is for the 20/78.08/4.9 $\mathrm{mm}$ mesh combination. The pressure drop decreases as the length of the 250 Mesh is increased. A suitable mesh size combination could be chosen depending on the system requirements. The performance parameters for a 250-300-400 mesh size combination with lengths of 20-78.08-4.91 mm respectively are given in Table 7 . The losses are plotted in Fig. 7 for the above combination of meshes. Regenerator effectiveness has increased by $0.16 \%$ and pressure drop during compression stroke has decreased by $29.2 \%$ when compared to the 400 mesh regenerator. The regenerator ineffectiveness is low at the entry and hence a still lower mesh size can be selected for the given operating conditions instead of the 250 mesh. Thus the hybrid regenerator is tested for the performance of regenerator of OPTR. The performance with single mesh regenerator and combination of meshes or hybrid regenerator is compared. For a combination of mesh sizes of 250, 300 and 400, an effectiveness of 0.9963 is obtained, an increase of $3 \%$.

\section{Discussion}

Performances predicted by the simulation program for an OPTR (Kral et al., 1992) under specific operating conditions are obtained. At $274 \mathrm{~K}$ the refrigerating effect of the program is $12.689 \mathrm{~W}$, whereas the actual experimental result is $11.57 \mathrm{~W}$, a difference of $8.5 \%$. An Effectiveness of 0.9907 is obtained for the 400 mesh regenerator with Pressure drop during Compression calculated as 0.1268 bar. The predicted refrigerating effect, drawn as a polynomial is compared with experimental results of Huang and $\mathrm{Yu}$ (2001). At $139 \mathrm{~K}$, the refrigerating effect predicted by the program is 3.378 $\mathrm{W}$, whereas the actual experimental result is $3 \mathrm{~W}$, a difference of $11.2 \%$.

A methodology is devised and incorporated in the simulation program to generate combinations of mesh sizes of regenerator confirming to the geometrical constraints of the PTR system. Combinations of 250, 300 and 400 mesh sizes are possible and a methodology is devised and incorporated in the simulation program to generate combinations confirming to the physical and geometrical constraints. The lengths of the 150 mesh in the 150-200-400 mesh combination regenerator in Huang and Yu's OPTR are varied from lengths of $10 \mathrm{~mm}$ to 60 $\mathrm{mm}$. The performance of the OPTR and regenerator in particular is calculated. Maximum refrigerating effect of the optr is obtained with the 20/57/74/32.25 mm lengths of the 150-200-400 mesh size combination. Even though the 10/70.14/29.85 mesh gives a higher effectiveness and a lower pressure drop, the higher losses due to conduction and reheat loss leads to lower refrigeration effect. Similarly, the performance of combination of meshes in kral's OPTR configuration with the length of 250 mesh size varying from $10 \mathrm{~mm}$ to $80 \mathrm{~mm}$ inside the regenerator tube are calculated and found that the maximum effectiveness of 0.9923 is for the 20/78.08/4.9 $\mathrm{mm}$ mesh combination. For a hybrid regenerator of 250300-400 mesh combination with lengths 20-78.086-4.913 $\mathrm{mm}$ respectively, the effectiveness is 0.9923 for a pressure drop of 0.0897 bar. The regenerator effectiveness has increased by $0.16 \%$ and the pressure drop during compression has decreased by $29.2 \%$ when compared to the 400 mesh regenerator.

\section{Conclusion}

A validated mathematical model, which can be used to simulate, design and optimize an OPTR for a given application is developed. As the difference between the predicted and actual experimental results is less $8.5 \%$ and $12 \%$ for Kral's and Huang and Yu's configuration respectively, the program is validated.

Performances predicted by the simulation program for the single mesh regenerator and a Hybrid regenerator (if inserted instead of a single mesh) for Kral's OPTR under specific operating conditions are obtained. The regenerator effectiveness has increased by $0.16 \%$ and the pressure drop during compression has decreased by $29.2 \%$ when compared to the single mesh (400 Mesh) regenerator. The performance of Hybrid regenerator with the length of 250 mesh size varying from $10 \mathrm{~mm}$ to 80 $\mathrm{mm}$ indicates that the maximum effectiveness of 0.9923 is for the $20 / 78.08 / 4.9 \mathrm{~mm}$ mesh combination. Hybrid Regenerators improves the refrigeration capacity of the OPTR system by as much as $40 \%$. Thus, the computer program can be used for the design of optr with hybrid regenerators for a given application.

\section{References}

1. Andeen BR (1982) Heat Capacity and Geometry Impacts on Regenerator Performance Adv. Cryo. Engg. 27, 611619.

2. Huang B.J. and Yu G.J., (2001) Experimental study on the design of orifice pulse tube refrigerator, International Journal of Refrigeration, 24, 400-408.

3. Gifford WE and Longsworth RC (1964) Pulse tube refrigeration. Trans. ASME: J. Eng. Ind. 86, 264.

4. Heggs PJ (1991) Design and Operational Flexibility of Thermal Regenerators, Heat Exchange Engg. Vol. 1, ed.by Foumeny and Heggs, Ellis Horwood Publication.

5. Kral SF, Dallas H, Jon R and Joseph J (1992) Test Results of an Orifice Pulse Tube Refrigerator. Adv. Cryogenic Engg. 37 (B), 931-937.

6. Radebaugh R (1990) A review of pulse tube refrigeration. Adv. Cryogenic Engg. 35, 1191-1205.

7. Thirumaleshwar M and Subramanyam SV (1986) Heat Balance analysis of single stage Gifford-McMohan cycle cryorefrigerator. Cryogenics. 26, 189-195.

8. Zhu SW and Chen ZQ (1994) Isothermal model of pulse tube refrigerator. Cryogenics. 34, 591-595.
Research article

(cIndian Society for Education and Environment (iSee)
"Cryogenic refrigerators " http://www.indjst.org
Jayaraman \& Senthil Kumar Indian J.Sci.Technol. 